\title{
Severe Dilated Cardiomyopathy in a Girl with Celiac Disease and Type 1 Diabetes
}

\author{
Mariam Ghozzi ${ }^{1,2}$, Chaima Mrizak ${ }^{1}$, Taha Hasnaoui ${ }^{3}$, Sonia Ernez ${ }^{3}$, Maha Kacem ${ }^{4}$, Asma \\ Ommezzine $^{5}$, Laarbi Chaieb ${ }^{4}$, Gouider Jridi ${ }^{3}$, Ibtissem Ghedira ${ }^{1,2 *}$ \\ ${ }^{1}$ Department of Immunology, Farhat Hached University Hospital, Sousse, Tunisia \\ ${ }^{2}$ Research Unit (03/UR/07-02), Faculty of Pharmacy, Monastir University, Tunisia \\ ${ }^{3}$ Department of Cardiology, Farhat Hached University Hospital, Sousse, Tunisia \\ ${ }^{4}$ Department of Endocrinology, Farhat Hached University Hospital, Sousse, Tunisia \\ ${ }^{5}$ Department of Biochemistry Sahloul University Hospital, Sousse, Tunisia
}

Received: November 10, 2015; Accepted: December 10, 2015; Published: January 04 , 2016

*Corresponding author: Ibtissem Ghedira, Laboratory of Immunology, Farhat Hached Hospital, Avenue Ibn El Jazzar, 4000 Sousse-Tunisia, Tel: (216) 73-221-411; Fax: (216) 73461830; Email: i_ghedira@yahoo.fr

\begin{abstract}
An 18-year-old girl was admitted for tachycardia and dyspnea of effort stage II of NYHA. Her medical history revealed a stroke four months ago and uncontrolled type 1 diabetes since the age of 10 years. Physical examination showed a short stature, pallor, muscular atrophy and delayed puberty but no diabetic neuropathy. Direct inquiry revealed that she has had clinical signs of classical celiac disease since the early infancy and secondary amenorrhea since two years. Ophtalmological examination did not show diabetic retinopathy. Echocardiography revealed the presence of a big thrombus, hypokinesis and dilated cardiomyopathy with a low rate of left ventricular ejection fraction at $20 \%$. Laboratory tests yielded a high level of B-type natriuretic peptide, anemia, vitamin D deficiency, hypocholesterolemia and low level of high density lipoprotein. Microalbuminuria was negative. All serological markers of celiac disease were highly positive. The patient was put on gluten free diet and she received a resynchronization cardiac therapy. We emphasize that celiac disease and type 1 diabetes must be kept in mind in etiological diagnosis of dilated cardiomyopathy.
\end{abstract}

Keywords: Dilated cardiomyopathy; Celiac disease, Type 1 diabetes, Anti-Endomysium antibodies; Tunisia

\section{Introduction}

Celiac disease (CD) is an autoimmune systemic disorder affecting genetically predisposed subjects. The multitude of extraintestinal manifestations of CD makes diagnosis difficult. It has been reported that patients with $C D$ were at increased risk of dilated cardiomyopathy (DCM) [1]. In the other hand, an increased prevalence of CD among patients with DCM has been described [2-6]. DCM has also been reported in T1D [7] and 75\% of patients with idiopathic DCM were found to be diabetic [8]. It has been demonstrated that patients with both CD and T1D have more severe complications than patients presenting T1D or CD only [9]. We present a case of DCM in an 18-year-old girl with both CD and T1D.

\section{Case Report}

An 18-year-old girl was admitted, in July 2014, to the cardiology department of our university hospital, for tachycardia and dyspnea of effort stage II of NYHA. Her medical history revealed a stroke in April 2014 and uncontrolled type 1 diabetes (T1D) since the age of 10 years.

Clinical examination showed a short stature (-1.8 SD), pallor, muscular atrophy and delayed puberty but no diabetic neuropathy.

Direct inquiry revealed chronic diarrhea, abdominal pain and bloating since the early infancy; weight loss since two years, late menarche (at the age of 15 years) and secondary amenorrhea since two years. There was no family history of cardiac disease.

On brain magnetic resonance imaging, multiple lesions of different dates and hematoma were seen. Echocardiography revealed the presence of a big thrombus $(5 \mathrm{~cm})$, hypokinesis and DCM with a low rate of left ventricular ejection fraction (LVEF) calculated with the modified biplane Simpson's rule at $20 \%$. Electrocardiogram showed an arrhythmia. Pelvic echography revealed a child's uterus. Abdominal echography showed embolic kidney damage. Bone densitometry showed osteopenia. Ophtalmological examination did not show diabetic retinopathy.

Laboratory tests yielded the following results: B-type natriuretic peptide: $689.6 \mathrm{pg} / \mathrm{ml}$ (normal values (NV) < 254), glycosylated hemoglobin: 11.9\% (NV: 5-7\%), hemoglobin: 10.6 g/dl (NV: 12-15.5), mean corpuscular volume: 82.6 (NV:83-98), iron: $7.08 \mu \mathrm{mol} / \mathrm{l}(\mathrm{NV}: 10-30)$, ferritin: $36 \mu \mathrm{g} / \mathrm{l}$ (NV:20-300), erythrocyte sedimentation rate $20 \mathrm{~mm}$ the first hour (NV: < 10 $\mathrm{mm}$ the first hour), C reactive protein (CRP) : 16g/l $(\mathrm{NV}<6)$, total cholesterol: $2.1 \mathrm{mmol} / \mathrm{l}$ (NV: 3.9-6.7), high density lipoprotein: $0.48 \mathrm{mmol} / \mathrm{l}$ (NV: 0.8-1.7), vitamin D: $13.2 \mathrm{ng} / \mathrm{ml}$ (NV: 20-40), alkaline phosphatase: $380 \mathrm{IU} / \mathrm{l}(\mathrm{NV}: 40-130)$ and total protein: 63 g/l (NV: 65-75). White blood cells, platelets, calcium, phosphorus, 
triglycerides, cardiac troponin I and thyroid hormones were normal. Microalbuminuria was negative. Antinuclear, anticardiolipin, anti- $\beta 2$ - glycoprotein and anti-neutrophil cytoplasmic antibodies were all negative. All serological markers of $\mathrm{CD}$ were highly positive: IgA anti-endomysium: +++, IgA anti-transglutaminase $2:>100 \mathrm{U} / \mathrm{ml}(\mathrm{NV}<25 \mathrm{U} / \mathrm{ml})$, IgA antideaminated gliadin peptides: $>200 \mathrm{RU} / \mathrm{ml}(\mathrm{NV}<25 \mathrm{RU} / \mathrm{ml}), \mathrm{IgG}$ anti-deaminated gliadin peptides: $145 \mathrm{RU} / \mathrm{ml}(\mathrm{NV}<25 \mathrm{RU} / \mathrm{ml})$.

A treatment with diuretic (furosemide), dobutamine, inhibitor of angiotensin I -converting enzyme (captopril), aldosterone antagonist (spironolactone), heparine infusion (enoxaparine) and oral anticoagulation with acenocoumarol was initiated. She is under insulin therapy since the age of 10 years. Once the diagnosis of CD was established, our patient was put on a gluten free diet (GFD) and a calcium, vitamin D and iron supplementation were initiated.

Four months later, anemia, diarrhea, bloating and abdominal pain disappeared. Total protein reverted to normal level and thrombus resolved. LVEF remained low (15\%). So the patient had received resynchronization cardiac therapy.

\section{Discussion}

In the present study, we have diagnosed CD in an 18-yearold girl. Our patient is treated with acenocoumarol, so no bowel biopsy could be done. EmA is now considered as the "gold standard" for the diagnostic of CD [10]. Moreover, it has been recently demonstrated that bowel biopsy is not always required to diagnose CD especially in patient with concordant antibody results [11].

Our patient was admitted for DCM. Common cardiovascular risk factors were eliminated and there was no cardiomyopathy in her family. That is why we could hypothesize that DCM could be due to CD or T1D or to both diseases. Although our patient had neither retinopathy nor nephropathy or neuropathy, DCM could be the unique complication of T1D [7]. DCM associated to CD (DCM-CD) without family history of cardiac disease and without known etiology was described especially as case reports $[12,13]$. It is interesting to know that in previously reported cases of DCM-CD, there was an improvement for cardiac function under GFD for those who had LVEF equal or more than $30 \%$. In the other hand, a worsening of cardiac function in patients who were not compliant with GFD was described $[12,13]$. Untreated CD patients might have a more severe clinical evolution of DCM compared to the natural evolution of the disease observed in patients with isolated DCM [14]

Many pathophysiological mechanisms could explain DCM in CD and in T1D. Our patient had uncontrolled diabetes. It has been reported that hyperglycemia after recovery from hypoglycemia worsens endothelial function and increases oxidative stress and inflammation [15]. In CD, the oxidative stress could be increased by toxic gliadin peptides and by decrease of antioxidant defenses [16]. In our patient, CD had caused vitamin D deficiency which is a risk factor for both T1D and cardiovascular disease [17].
Carnitine deficiency, due to both malabsorption syndrome secondary to $\mathrm{CD}$ and to alteration of gut microbiota, is a risk factor for cardiovascular disease [18]. Our patient has both CD and T1D and these two autoimmune diseases are associated with compositional changes in gut microbita $[19,20]$. Both in CD and in T1D intestinal permeability are altered. Increased systemic absorption of various luminal antigens and infectious agents could cause myocardial damage secondary to immune mediated mechanisms.

In conclusion, DCM associated with both $\mathrm{CD}$ and T1D is a serious and potentially lethal condition which requires multidisciplinary approach involving cardiologists, endocrinologists, gastroenterologists, immunologists and nutritionists.

\section{Acknowledgement}

This study is supported by: Research Unit (03/UR/07-02), Faculty of Pharmacy, Monastir University, Tunisia.

\section{References}

1. Emilsson L, Andersson B, Elfström P, Green PH, Ludvigsson JF. Risk of idiopathic dilated cardiomyopathy in 29000 patients with celiac disease. J Am Heart Assoc. 2012;1:e001594. doi: 10.1161/ JAHA.112.001594.

2. Curione M, Barbato M, De Biase L,Viola F, Lo Russo L, Cardi E. Prevalence of coeliac disease in idiopathic dilated cardiomyopathy. Lancet. 1999;354(9174):222-223. DOI: 10.1016/S0140-6736(99)01501-9.

3. Not T, Faleschini E, Tommasini A, Repetto A, Pasotti M, Baldas $\mathrm{V}$, et al. Celiac disease in patients with sporadic and inherited cardiomyopathies and in their relatives. Eur Heart. 2003;24(15):14551461.

4. De Bem RS, Da Ro Sa Utiyama SR, Nisihara RM, Fortunato JA, Tondo JA, Carmes ER, et al. Celiac disease prevalence in Brazilian dilated cardiomyopathy patients. Dig Dis Sci. 2006;51(5):1016-1019.

5. Chicco D, Taddio A, Sinagra G, Di Lenarda A, Ferrara F, Moretti M, et al. Speeding up coeliac disease diagnosis in cardiological settings. Arch Med Sci. 2006;6(5):728-732. doi: 10.5114/aoms.2010.17088.

6. Zahmatkeshan M, Fallahpoor M, Amoozgar $H$. Prevalence of celiac disease in children with idiopathic dilated cardiomyopathy. Iran J Pediatr. 2014;24(5):587-592.

7. Büyükgebiz A, Saylam G, Dündar B, Böber E, Unal N, Akcoral A. Dilated cardiomyopathy as the first early complication in a 14 yearold girl with diabetes mellitus type 1. J Pediatr Endocrinol Metab. 2000;13(8):1143-1146.

8. Bertoni AG, Tsai A, Kasper EK, Brancati FL. Diabetes and idiopathic cardiomyopathy: a nationwide case-control study. Diabetes Care. 2003;26(10):2791-2795.

9. Pitocco D, Giubilato S, Martini F, Zaccardi F, Pazzano V, Manto A, et al. Combined atherogenic effects of celiac disease and type 1 diabetes mellitus. Atherosclerosis. 2011;217(2):531-535. doi: 10.1016/j. atherosclerosis.2011.04.042.

10. Husby S, Koletzko S, Korponay-Szabó IR, Mearin ML, Phillips A, Shamir $\mathrm{R}$, et al. European Society for Pediatric Gastroenterology, Hepatology, and Nutrition guidelines for the diagnosis of coeliac disease. J 
Pediatr Gastroenterol Nutr. 2012;54(1):136-160. doi: 10.1097/ MPG.0b013e31821a23d0.

11. Bürgin-Wolff A, Mauro B, Faruk H. Intestinal biopsy is not always required to diagnose celiac disease: a retrospective analysis of combined antibody tests. BMC Gastroenterol. 2013;23:13-19. doi: 10.1186/1471-230X-13-19.

12. Curione M, Barbato M, Viola Fet, Francia P, De Biase L, Cucchiara S. Idiopathic dilated cardiomyopathy associated with coeliac disease: the effect of a gluten-free diet on cardiac performance. Dig Liver Dis. 2002;34(12):866-869.

13. Milisavljević N, Cvetković M, Nikolić G, Filipović B, Milinić N. Dilated cardiomyopathy associated with celiac disease: case report and literature review. Srp Arh Celok Lek. 2012;140(9-10):641-643.

14. Curione M, Danese C, Viola F, Di Bona S, Anastasia A, Cugini P, et al. Carnitine deficiency in patients with coeliac disease and idiopathic dilated cardiomyopathy. Nutr Metab Cardiovasc Dis. 2005;15(4):279283.

15. Ceriello A, Novials A, Ortega E, La Sala L, Pujadas G, Testa R, et al. Evidence that hyperglycemia after recovery from hypoglycemia worsens endothelial function and increases oxidative stress and inflammation in healthy control subjects and subjects with type 1 diabetes. Diabetes. 2012;61(11):2993-2997. doi: 10.2337/db120224 .
16. Ferretti G, Bacchetti T, Masciangelo S, Saturni L. Celiac disease, inflammation and oxidative damage: a nutrigenetic approach. Nutrients. 2012;4(4):243-257. doi: 10.3390/nu4040243.

17. Gangula PR, Dong YL, Al-Hendy A, Gloria Richard-Davis, MontgomeryRice Valerie, Georges Haddad, et al. Protective cardiovascular and renal actions of vitamin D and estrogen. Front Biosci (Schol Ed). 2013;5:134-148.

18. Ussher JR, Lopaschuk GD, Arduini A. Gut microbiota metabolism of L-carnitine and cardiovascular risk. Atherosclerosis. 2013;231(2):456461.

19. Wacklin P, Kaukinen K, Tuovinen E, Collin P, Lindfors K, Partanen J, et al. The duodenal microbiota composition of adult celiac disease patients is associated with the clinical manifestation of the disease. Inflamm Bowel Dis. 2013;19(5):934-941.

20. Murri M, Leiva I, Gomez-Zumaquero JM, Tinahones FJ, Cardona F, Soriguer F, et al. Gut microbiota in children with type 1 diabetes differs from that in healthy children: a case-control study. BMC Med. 2013;11:46-58. doi: 10.1186/1741-7015-11-46. 